\title{
Method to Recycle Paper Sludge Waste: Production of Panels for Sound Absorption Applications
}

\author{
Tomas ASTRAUSKAS ${ }^{1 *}$, Raimondas GRUBLIAUSKAS ${ }^{2}$ \\ ${ }^{1,2}$ Department of Environmental protection and water engineering, Vilnius Gediminas Technical \\ University, Saulètekio al. 11, Vilnius, Lithuania
}

\begin{abstract}
Paper sludge is the water treatment waste, which produced during paper production. Paper sludge (PS) waste utilization is the common problem in the EU and internationally. According to the waste management directive No. 2008/98/EC, paper sludge waste should not be utilized in landfills. In the European Union, alone 93 million tons of PS generated yearly. Nowadays most of the paper sludge waste used as fuel for incineration power plants (up to $55 \%$ ). According to waste management legislation such waste management should be avoided as well. Very small portion $(10 \%)$ of PS is used in construction sector. In construction, paper sludge used as additive in concrete composite materials. Such legislation of waste management generates the motivation of this study. In this study authors propose to produce composite panels in which PS is the main material of composite. As the binding material, clay proposed due to its good binding properties and therefore its natural material. Such produced panels proposed to use it for sound absorption applications. To determine composites sound absorption coefficient standard ISO 10534-2 method was used. The sound absorption coefficient in different octave bands reached up to 0.59 .
\end{abstract}

Keywords - CLAY; composite materials; paper sludge; recycling; sound absorption

\begin{tabular}{|lll}
\hline Nomenclature & & \\
$H_{12}$ & Transfer function between microphone & Pa \\
$p_{1}, p_{2}$ & Pressure in microphones 1 and 2 & $\mathrm{mm}$ \\
$S$ & Distance between microphones & $\mathrm{mm}$ \\
$X_{1}$ & Distance between microphone No. 1 and sample & $\mathrm{mm}$ \\
$X_{2}$ & Distance between microphone No. 2 and sample & - \\
$H_{\mathrm{I}}$ & Transfer function for incident wave alone & - \\
$H_{\mathrm{R}}$ & Transfer function for reflected wave alone & $\mathrm{m}^{-1}$ \\
$k_{0}$ & Wave number & - \\
$R$ & Sound reflection coefficient & - \\
$\alpha$ & Sound absorption coefficient &
\end{tabular}

* Corresponding author.

E-mail address: tomas.astrauskas@vgtu.lt 


\section{INTRODUCTION}

Noise in general becomes more and more discussed topic in the public. According to the EU statistics about $40 \%$ of population is exposed to road, air or rail traffic and noise levels exceed $55 \mathrm{~dB}(\mathrm{~A})$ [1]. The most those people are exposed to the traffic noise [2]. One of the solutions to reduce the noise levels is to use sound absorbing materials.

Paper sludge is the water treatment waste, which produced during paper production. Paper sludge (PS) waste utilization is the common problem in the EU and internationally [3]. According to authors Frias et al. paper sludge is the main waste in the paper processing factories, the percentage reach $35 \%$ of product volume [4]. According to the waste management directive No. 2008/98/EC, paper sludge waste should not be utilised in landfills. This article deals with paper sludge as sound absorbing material.

PS is generated in different technological processes in paper production or recycling chain. According to its composition of components paper sludge divided into two sludge groups:

Primary sludge - such sludge contains lignocellulose components (cellulose, lignin), binding materials of the paper (kaolin, calcium carbonate) [5], [6].

Ink sludge - such sludge contains ink from the recycled paper, small fibres of cellulose which cannot be regenerated for paper recycling, the remains of solution for ink removal [7], [8].

PS waste management problem becoming more important recent years in European Union and internationally. The PS waste is banned from landfilling in EU. Most of the PS in EU is not used for the recycling. According to Confederation of European paper industries only $10 \%$ of PS was recycled in 2016 [9]. In Fig. 1 is shown that $55 \%$ of PS is used for energy recovery which according to waste management guidelines is not good way to treat waste in long term.

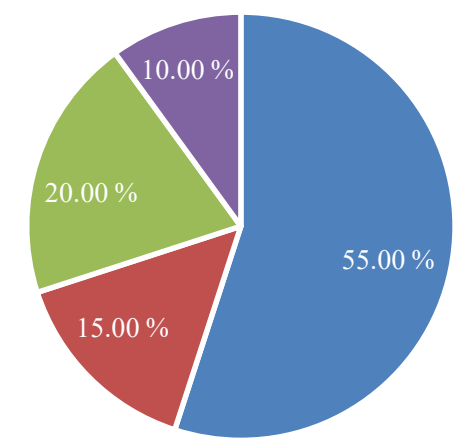

- Energy recovery $\quad$ Composting $\quad$ Storing in the sites $\quad$ Recycling in other industries

Fig. 1. Management of PS in European union, 2017 [9].

According to the recent studies PS could be used as raw material in several industry sectors:

- Biogas production. The PS contains from $45 \%$ to $55 \%$ percent of organic matter which shows that PS has potential for such waste treatment. Such data shows great 
potential for PS to be used for biogas production [10]-[14];

- The other studies show that PS could be used for Biochar production. Such biochar could be used for soil treatment from zinc [15]-[17];

- In the construction materials. Most of the recent studies the PS potential to be used as additive for concrete to make the bricks lighter. The studies show that addition of PS to the bricks increase thermal insulation of the bricks, but reduces its robustness and strength [4], [18]-[21].

Most of the PS recycling is in the construction sector. Studies show that PS could be used for bricks to be made more porous. Such technique uses PS to create air gaps inside which reduced thermal conductivity. The technique air gaps are created during brick burning process, during this stage brick production PS burns and leaves air gaps inside the bricks. The downside of such technique that the strength of the brick is being reduced as well. Similar studies were performed with clay, ceramic bricks [22]-[23].

Another way to use PS is in the composite materials, several were made focusing on cement, wood chip composite with PS. Studies on composites containing PS and wood fibers, plastic or cement has shown that addition of PS reducing the overall strength of the composite. The optimal quantity of PS in most of the studies reach $10 \%$ of overall mass [24]-[27].

Very few studies were made focusing on such composites acoustic properties. Most of the studies focusing on PS as additive to other known construction materials. This work focused on PS as main the material of the composite. In the most of other author works, the PS not considered as the main material in composite. The aim of this paper is to propose a method to produce PS and clay composite panels for sound absorption applications. The results gained in this study could be used in further PS composite development.

\section{Methods}

PS used within the work was taken as a raw material from paper production company of Lithuania. The PS was obtained from different sides of the sludge pile. The sludge is a mixture of primary (pulp mill) and secondary (ink) sludges. The PS was dried at $60{ }^{\circ} \mathrm{C}$ in a drier and mixed every three days to achieve an effective drying process. The preparation of the paper sludge took 14 days on average, because of the high humidity of raw paper sludge. The dry paper sludge was crushed with a gill crusher and sorted. For PS composite panel sample making 1-2.5 mm grain size was used.

The proposed method to build up an acoustic panel made of PS composite using perforated boxes. In order to avoid the drawbacks related to the fragility and inhomogeneity of the composites. Lightweight, compact and robust acoustic panels designed for sound absorption applications.

Composites were obtained by mixing grains of PS and clay. To bind the clay and PS grains the water was used. While making clay and PS composite samples it was noticed that depending on clay quantity in the sample, the water quantity needed to make homogenous mixture changes as well. The mixture of clay and PS grains was dried in $50{ }^{\circ} \mathrm{C}$ for 3 days. To test sound absorption coefficient depending on composition of four samples were made by changing PS amount in the composition from 50-80\% in steps of $10 \%$. While preparing samples it was noticed that higher values of PS (90\%) is not appropriate, because sample do not bind good enough and becomes fragile. Therefore, acoustic properties of such sample cannot be tested due to its fragility. 
A square sample box has been designed and 3D printed using polylactic acid (see Fig. 2a). The bottom of the container has been perforated with circular holes of $2 \mathrm{~mm}$ diameter in a square lattice of $3.5 \mathrm{~mm}$. The function of the holes is to ensure the diffuseness of water drying.

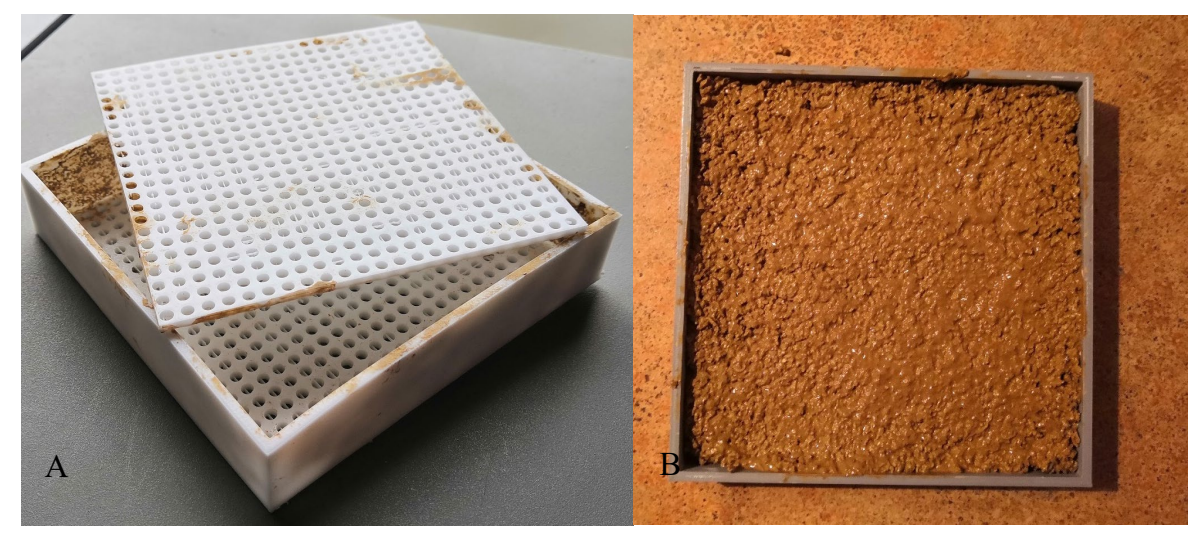

Fig. 2. Sample producing box. A) box with a top cover and B) box with the composite sample inside.

A top perforated layer has also been printed to close the box from the top. The samples were pressed and flipped every 2 hours during the drying period, this way the samples experience the gravity force from both sides, therefore clay do not travel to one side of the sample. The pressure of $120 \mathrm{~Pa}$ applied to the sample to ensure that the shape of the sample do not change while drying. In 3 days, a square acoustic panel of $10 \mathrm{~cm}^{2}$ and $13 \pm 1 \mathrm{~mm}$ thickness obtained using this container. In total 4 containers were used for sample making. In Fig. 3 dried PS and clay composite panels are presented. Due to its fragility, $90 \%$ PS and clay composite panels were not tested, because it was nearly impossible to get representative data.

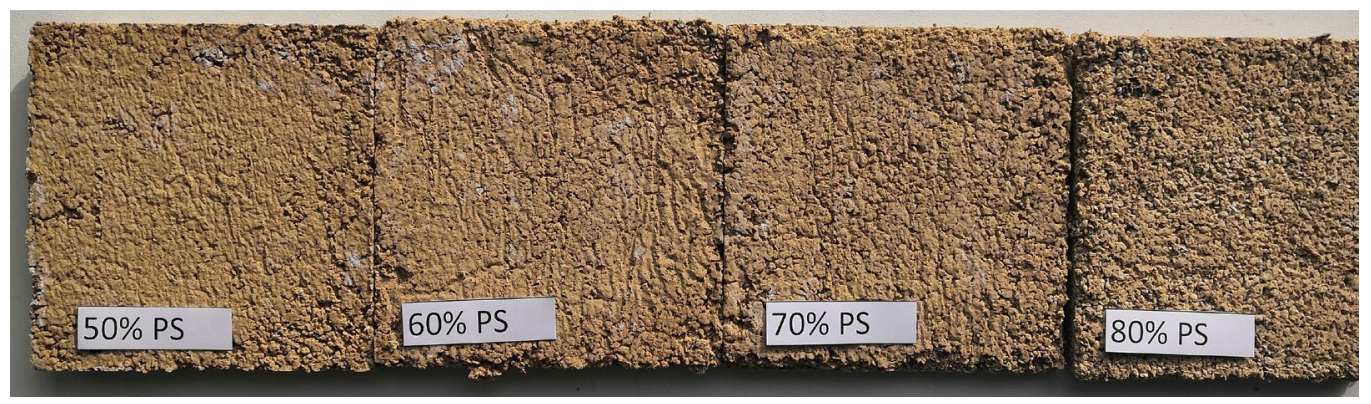

Fig. 3. Dried PS and clay composite panels.

For obtaining the sound absorption coefficient $(\alpha)$ of the paper sludge composites, the ISO 10534-2 standard method was used [28]. The cross section of the tube was squared of $10 \mathrm{~cm}$ side. Composite panels built to fit into the tube. The samples were rigidly backed. The experimental set up is shown in Fig. 4. The distances from the sample to the microphones are $X_{1}=190 \mathrm{~mm} ; X_{2}=100 \mathrm{~mm}$ and the distance between microphones $S=90 \mathrm{~mm}$. The working frequency range is from 200 to $1600 \mathrm{~Hz}$. The results are presented using $1 / 3$ octave band filtering. 


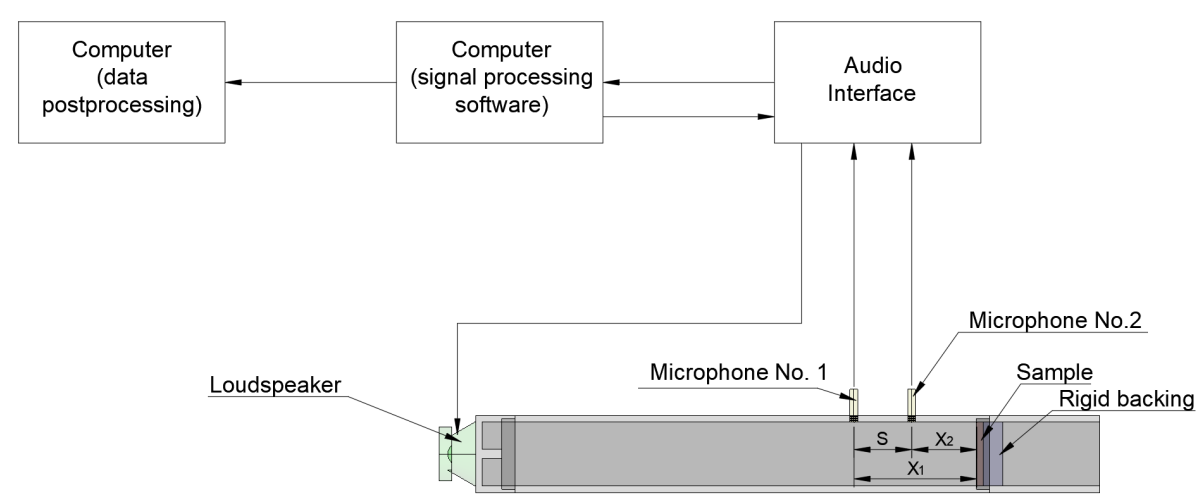

Fig. 4. Impedance tube system used for measurements. $S=90 \mathrm{~mm}, X_{1}=190 \mathrm{~mm}, X_{2}=100 \mathrm{~mm}$.

The tests were made according to the methodology described in ISO 10534-2 standard. Transfer function method was used, two microphone technique.

The transfer function $H_{12}$ Eq. (1) between microphone positions calculated as the pressure ratio between pressures measured by both microphones. Transfer function for incident wave alone $H_{\mathrm{I}}$ and transfer function for reflected wave alone $H_{\mathrm{R}}$ calculated according Eq. (2) and Eq. (3) [28].

$$
\begin{gathered}
H_{12}=\frac{p_{2}}{p_{1}} \\
H_{\mathrm{I}}=\frac{p_{2 \mathrm{I}}}{p_{1 \mathrm{I}}}=e^{-\mathrm{j} k_{0}\left(x_{1}-x_{2}\right)} \\
H_{\mathrm{R}}=\frac{p_{2 \mathrm{R}}}{p_{1 \mathrm{R}}}=e^{\mathrm{j} k_{0}\left(x_{1}-x_{2}\right)}
\end{gathered}
$$

From Eq. (1), Eq. (2) and Eq. (3) the reflection coefficient of the sample can be calculated as:

$$
R=\frac{H_{12}-H_{\mathrm{I}}}{H_{\mathrm{R}}-H_{12}} e^{2 \mathrm{j} k_{0} x_{1}},
$$

where $R$ is the reflection coefficient of the sample, $k$ is the wavenumber, $x_{1}=100 \mathrm{~mm}$ is the distance between the sample and microphone No. 1 .

Finally, the sound absorption coefficient is calculated using the following Eq. (5).

$$
\alpha=1-|R|^{2}
$$

The sound absorption is the inverse parameter to the sound reflection. Sound absorption and reflection parameters are relative to the total amount of energy, that falling on the material. These parameters vary from 0 to 1 , and it is dimensionless. 


\section{RESUlTS AND DisCUSSION}

Using the method described, four PS and clay composite panels were produced and tested. Due to different amount of clay in the composition the values of density vary between the samples. In table No. 1 the density parameters of the samples are presented.

In Table 1 it is shown that the density decreases as PS amount in the composite is increased. Such results show that composites with less amount of PS has a potential to be used for sound insulation applications.

TABle 1. Density of Produced Samples

\begin{tabular}{llll}
\hline $\begin{array}{l}\text { Sample } \\
\text { No. }\end{array}$ & $\begin{array}{l}\text { Percentage of PS } \\
\text { in composite, } \%\end{array}$ & $\begin{array}{l}\text { Percentage of clay } \\
\text { in composite, } \%\end{array}$ & $\begin{array}{l}\text { Density, } \\
\mathbf{k g} / \mathbf{m}^{3}\end{array}$ \\
\hline 1 & 50 & 50 & 1098.8 \\
2 & 60 & 40 & 886.9 \\
3 & 70 & 30 & 752.6 \\
4 & 80 & 20 & 627.9 \\
\hline
\end{tabular}

In Fig. 5 the sound absorption results of different composite panels presented. The results of all samples show that sound absorption coefficient values increase with frequency. Low frequency values are low because of relatively small thickness $(\approx 10 \mathrm{~mm})$. The panels with lower PS quantity $(50 \% ; 60 \%)$ in the composition showed higher sound absorption coefficient values lower frequencies $(250-1000 \mathrm{~Hz})$. The sound absorption coefficient values of mentioned composite panels peaks at $1 \mathrm{kHz}$. Sound absorption coefficient of $50 \%$ PS composite panel reach 0.48 .

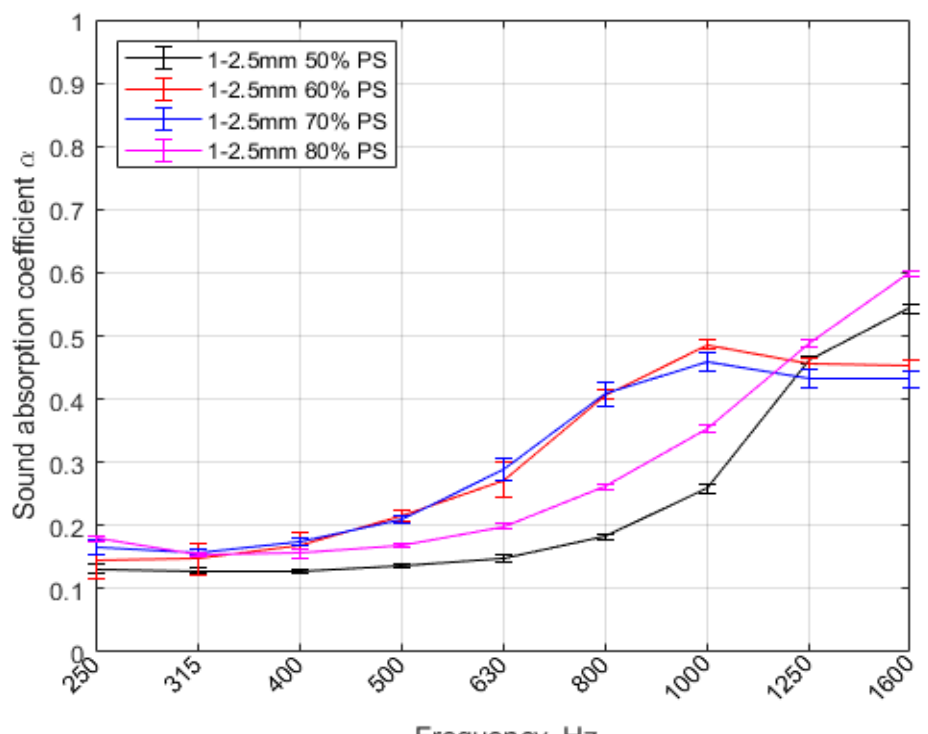

Frequency, $\mathrm{Hz}$

Fig. 5. Result comparison between composites. 
Composite panel of $60 \%$ PS showed similar behaviour compared with $50 \%$ PS panel. The results show that sound absorption coefficient values increase with frequency. Similar to $50 \%$ panels sound absorption coefficient is lower in lower frequencies. The sound absorption coefficient values start to increase from $630 \mathrm{~Hz}$. Sound absorption coefficient $\alpha$ is highest in $1 \mathrm{kHz}$ octave band and reach 0.5 .

The panels with $70 \%$ PS showed different behaviour compared with $50 \%$ and $60 \%$ panels. The results show that sound absorption coefficient values increase with frequency. The sound absorption coefficient values start to increase from $500 \mathrm{~Hz}$. Sound absorption coefficient $\alpha$ is highest in $1.6 \mathrm{kHz}$ octave band and reach 0.55 . Due to limitations of measurement equipment the peak values of this composition were not found. Potentially the peak values of this composition are in higher frequencies.

The composite of $80 \%$ PS showed similar behaviour to $70 \%$ PS composition. The results show that sound absorption coefficient values increase with frequency. The sound absorption coefficient values start to increase from $500 \mathrm{~Hz}$. Sound absorption coefficient $\alpha$ is highest in $1.6 \mathrm{kHz}$ octave band and reach 0.59 . As with $70 \%$ composite peak values were not found.

When comparing all tested composites, the results show that composites with less PS in it absorb sound better in lower frequencies $(250-1000 \mathrm{~Hz})$ but less in higher $(1250-1600 \mathrm{~Hz})$. Such behaviour could be linked to higher density of samples which had less PS in its composition.

The tested PS and clay composites showed similar results in lower frequencies, up to $500 \mathrm{~Hz}$. Such similarity depends on thickness of the sample. It is well known that sound absorption is efficient in $1 / 4$ of wavelength. Since the sample thickness was kept constant, $(13 \pm 1 \mathrm{~mm})$ the sound absorption composite sound absorption in lower frequencies were similar.

In higher frequencies, from $500 \mathrm{~Hz}$ to $1.6 \mathrm{kHz}$ the sample behaviour varies. Such difference could be addressed to porosity changes due to change of composition of clay and PS. The best sound absorption values were found when testing composite with $80 \%$ PS ( $\alpha$ reach to $0.59)$.

The proposed method shows that it is possible to design the panel which works for sound absorption applications. In further studies different PS grain size will be investigated. It is known that granular media porosity greatly depends on grain size, such phenomenon needs investigation of PS with clay composition.

Even though the method to produce PS and clay composite panels was proposed, it needs further investigation. It was noticed that several samples were uneven and needed remaking. The process of sample making will be adjusted in further studies in order to achieve panels with perfectly even walls. Such limitation of sample making can be seen in Fig. 5 and Fig. 6, where sound absorption coefficient slightly decreases in higher frequencies. Such phenomenon shows that there was very small air gap behind sample while measuring due to not even back surface of the sample.

\section{CONClusion}

With this study proposed method to produce robust acoustic panels where the main material is PS. Using clay as binder allowed to make samples, which was robust enough to test them without any difficulty. Although decreasing clay quantity in composition showed that samples became fragile. The proposed method shows the potential way for PS to be recycled.

The sound absorption coefficient values increase when density of composition decreases. The study shows that $50-60 \%$ PS samples are too dense to achieve effective sound 
absorption. The optimal sound absorption coefficient values were found in $80 \%$ PS composite ( $\alpha$ reach to 0.59 ). For sound absorption application such panels could be used with air gap behind panel to achieve better sound absorption with the same panel.

\section{REFERENCES}

[1] European Environment Agency. Exposure of Europe's population to environmental noise 2019. https://www.eea.europa.eu/data-and-maps/indicators/exposure-to-and-annoyance-by-2/assessment-4

[2] Aditya K., Chowdary V. Influence of Honking on the Road Traffic Noise Generated at Urban Rotaries for Heterogeneous Traffic. Environmental and Climate Technologies 2020:24(1):23-42. https://doi.org/10.2478/rtuect2020-0002.

[3] Bajpai P. Management of pulp and paper mill waste. Springer, 2015. https://doi.org/10.1007/978-3-319-11788-1

[4] Frías M., Rodríguez O., Sánchez de Rojas M. I. Paper sludge, an environmentally sound alternative source of MKbased cementitious materials. A review. Construction Building Materials 2015:74:37-48. https://doi.org/10.1016/j.conbuildmat.2014.10.007

[5] Ochoa de Alda J. A. G. Feasibility of recycling pulp and paper mill sludge in the paper and board industries. Resources, Conservation and Recycling 2008:52:965-972. https://doi.org/10.1016/j.resconrec.2008.02.005

[6] Kairytė A. Biopoliuretano putų, modifikuotu popieriaus gamybos atliekomis, tyrimai. (Investigations of biopolyurethane foam modified as waste from paper production). Vilnius Gediminas Technical University 2017. (In Lithuanian).

[7] Monte M. C., Fuente E., Blanco A., Negro C. Waste management from pulp and paper production in the European Union. Waste Management 2009:29(1):293-308. https://doi.org/10.1016/j.wasman.2008.02.002

[8] Jackson M. J., Line M. A., Wilson S., Hetherington S. J. Application of Composted Pulp and Paper Mill Sludge to a Young Pine Plantation. Journal of Environmental Quality 2000:29(2):407-414. https://doi.org/10.2134/jeq2000.00472425002900020006x

[9] Confederation of European Paper Industries. Key Statistics 2016. European Pulp \& Paper Industry. 2017. [Online]. [Accessed 15.02.2020]. Available: https://www.cepi.org/key-statistics-2016/

[10] Priadi C.,Wulandari D., Rahmatika D, Rahmatika I., Moersidik Setyo S. Biogas Production in the Anaerobic Digestion of Paper Sludge. APCBEE Procedia 2014:9:65-69. https://doi.org/10.1016/j.apcbee.2014.01.012

[11] Alvarez R., Villca S., Lidén G. Biogas production from llama and cow manure at high altitude. Biomass and Bioenergy 2006:30(1):66-75. https://doi.org/10.1016/j.biombioe.2005.10.001

[12] Lin Y., Wang D., Li Q., Xiao M. Mesophilic batch anaerobic co-digestion of pulp and paper sludge and monosodium glutamate waste liquor for methane production in a bench-scale digester. Bioresource Technology 2011:102(4):36733678. https://doi.org/10.1016/j.biortech.2010.10.114

[13] Kolbl S., Forte-Tavčer P., Stres B. Potential for valorization of dehydrated paper pulp sludge for biogas production: Addition of selected hydrolytic enzymes in semi-continuous anaerobic digestion assays. Energy 2017:126:326-334. https://doi.org/10.1016/j.energy.2017.03.050

[14] do Carmo Precci Lopes A, Mudadu Silva C, Pereira Rosa A, de Ávila Rodrigues F. Biogas production from thermophilic anaerobic digestion of kraft pulp mill sludge. Renewable Energy 2017:124:40-49. https://doi.org/10.1016/j.renene.2017.08.044

[15] Méndez A., Paz-Ferreiro J., Araujo F., Gascó G. Biochar from pyrolysis of deinking paper sludge and its use in the treatment of a nickel polluted soil. Journal of Analytical and Applied Pyrolysis 2014:107:46-52. https://doi.org/10.1016/J.JAAP.2014.02.001

[16] Paz-Ferreiro J., Plasencia P., Gascó G., Méndez A. Biochar from Pyrolysis of Deinking Paper Sludge and Its Use in the Remediation of Zn-polluted Soils. Land Degradation \& Development 2016:28(1):355-360. https://doi.org/10.1002/ldr.2597

[17] Zwieten Van L., Kimber S., Morris S., Chan K. Y., Downie A., Rust J., Joseph S., Cowie A. Effects of biochar from slow pyrolysis of papermill waste on agronomic performance and soil fertility. Plant and Soil 2010:327:235-246. https://doi.org/10.1007/s11104-009-0050-x

[18] Sutcu M., Akkurt S. The use of recycled paper processing residues in making porous brick with reduced thermal conductivity. Ceramics International 2009:35(7):2625-2631. https://doi.org/10.1016/j.ceramint.2009.02.027

[19] Goel G., Kalamdhad A. S. Paper mill sludge (PMS) and degraded municipal solid waste (DMSW) blended fired bricks-a review. MOJ Civil Engineering 2018:4:81-85. https://doi.org/10.15406/mojce.2018.04.00101

[20] Sarkar R., Kurar R., Gupta A. K., Mudgal A., Gupta V. Use of paper mill waste for brick making. Civil \& Environmental Engineering 2017. https://doi.org/10.1080/23311916.2017.1405768

[21] Munir M. J., Kazmi S. M. S., Wu Y., Hanif A., Khan M. U. A. Thermally efficient fired clay bricks incorporating waste marble sludge: An industrial-scale study. Journal of Cleaner Production 2018:174:1122-1135. https://doi.org/10.1016/j.jclepro.2017.11.060 
[22] Cusidó J. A., Cremades L. V., Soriano C., Devant M. Incorporation of paper sludge in clay brick formulation: Ten years of industrial experience. Applied Clay Science 2015:108:191-198. https://doi.org/10.1016/J.CLAY.2015.02.027

[23] Sutcu M., Akkurt S., Bayram A., Uluca U. Production of anorthite refractory insulating firebrick from mixtures of clay and recycled paper waste with sawdust addition. Ceramics International 2012:38(2):1033-1041. https://doi.org/10.1016/j.ceramint.2011.08.027

[24] Goel G., Kalamdhad A. S. An investigation on use of paper mill sludge in brick manufacturing. Construction and Building Materials 2017:148:334-343. https://doi.org/10.1016/j.conbuildmat.2017.05.087

[25] Soucy J., Koubaa A., Migneault S., Riedl B. The potential of paper mill sludge for wood-plastic composites. Industrial Crops and Products 2014:54:248-256. https://doi.org/10.1016/j.indcrop.2014.01.013

[26] Geng X., Zhang S. Y., Deng J. Characteristics of Paper Mill Sludge and Its Utilization for the Manufacture of Medium Density Fiberboard. Wood and Fiber Science 2007.

[27] Cavdar D. A., Yel H., Boran S., Pesman E. Cement type composite panels manufactured using paper mill sludge as filler. Construction and Building Materials 2017:142:410-416. https://doi.org/10.1016/j.conbuildmat.2017.03.099

[28] ISO 10534-2 Acoustics- Determination of Sound Absorption Coefficient and Impedance in Impedance Tubes. International Organization for Standardization. 2001 